\title{
Structure and Conceptual Design of a Water-Hammering-Type Honsang for Restoration
}

\author{
Yong Sam Lee ${ }^{1,2 \dagger}$ and Sang Hyuk Kim ${ }^{3}$ \\ ${ }^{1}$ Department of Astronomy and Space Science, Chungbuk National University, Cheongju 361-763, Korea \\ ${ }^{2}$ Chungbuk National University Observatory, Cheongju 361-763, Korea \\ ${ }^{3}$ Korea Astronomy and Space Science Institute, Daejeon 305-348, Korea
}

We analyzed the manufacturing procedure, specifications, repair history, and details of celestial movements of the waterhammering type Honsang (celestial globe). Results from our study on the remaining Honsangs in China and Japan and on the reconstruction models in Korea were applied to our conceptual design of the water-hammering type Honsang. A Honui (armillary sphere) and Honsang using the water-hammering method were manufactured in Joseon in 1435 (the 17th year of King Sejong). Jang Yeong-Sil developed the Honsang system based on the water-operation method of Shui yün $i$ hsiang t'ai in China. Water-operation means driving water wheels using a water flow. The most important factor in this type of operation is the precision of the water clock and the control of the water wheel movement. The water-hammering type Honsang in Joseon probably adopted the Cheonhyeong (天衡; oriental escapement device) system of Shui yün i hsiang t'ai in China and the overflow mechanism of Jagyeongnu (striking clepsydra) in Joseon, etc. In addition to the Cheonryun system, more gear instruments were needed to stage the rotation of the Honsang globe and the sun's movement. In this study, the waterhammering mechanism is analyzed in the structure of a water clock, a water wheel, the Cheonhyeong system, and the Giryun system, as an organically working operation mechanism. We expect that this study will serve as an essential basis for studies on Heumgyeonggaknu, the water-operating astronomical clock, and other astronomical clocks in the middle and latter parts of the Joseon dynasty.

Keywords: Honsang (celestial globe), water-hammering method, astronomical clock

\section{INTRODUCTION}

Honsang (渾象; celestial globe) is an ancient model of the celestial sphere, which is now called a celestial globe or star globe. Various types of Honsang were manufactured across the ages both in the East and the West and formed an important category of astronomical instruments among the scientific artifacts of astronomy.

In China since the Tang dynasty, instruments for celestial observations had been called Honui (armillary sphere) and those for representing the movement of stars on the celestial sphere called Honsang (Hahn et al. 2001, Kim 2002). ${ }^{1}$ The first records on Honsang in Korea are found in the Sejong era. A Honsang in that period was formed of a body of globe, made rotate around a north-south polar axis, and operated by a water-hammering method using water power. The surface of the globe was marked by degree numbers in horizontal and vertical lines, and by the equator, the ecliptic, and positions of stars to track the stars on the sky. It was also used to show the sun's movement along time and seasons by having the position of the sun move on the ecliptic.

In this study, we describe historical facts on the waterhammering type Honsang in Joseon based on the literature and introduce the manufacturing procedure of our Honsang model which has already been restored. System components

${ }^{1}$ In naming an armillary sphere, Honui and Honsang are distinguished today, but they were mixed to be Honcheonui in the past. (c) This is an open Access article distributed under the terms of the Creative Commons Attribution Non-Commercial License (http:// creativecommons.org/licenses/by-nc/3.0/) which premits unrestricted non-commercial use, distribution, and reproduction in any medium, provided the original work is properly cited.
Received Apr 3, 2012 Revised May 10, 2012 Accepted May 24, 2012 ${ }^{\dagger}$ Corresponding Author

E-mail: leeysam@hanmail.net

Tel: +82-43-261-2314 Fax: +82-43-274-2312 


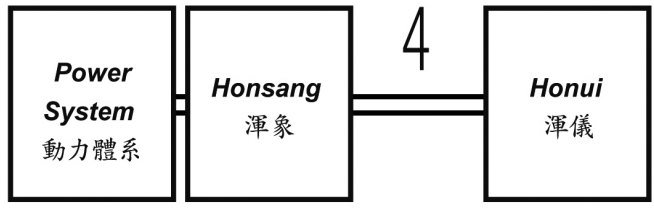

(a)

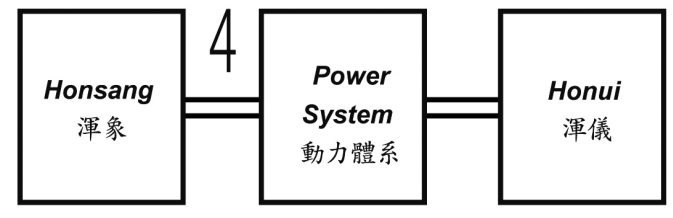

(b)

Fig. 1. Two arrangement types of Honui and Honsang with respect to the power system.

of the water-hammering type Honsang are also analyzed.

\section{MANUFACTURE HISTORY AND LITERATURE ON HONSANG}

The very first literature in Korea regarding Honsang is the record in 1437 (the 19th year of King Sejong) found in Sejong sillok (世宗實錄; history book during the Sejong era). This record says about the material and size of Honsang, the marking of degree numbers, the equator and the ecliptic, the rotation of the celestial sphere, the sun's movement on the ecliptic, and the power by the water-hammering method. The record in Sejong sillok is as follows.

\section{The 19th Year of King Sejong (1437) April 15th (Gap Sul)}

The Honui and Honsang have been placed in a small house to the west of the gnomon, where the Honui is in the east and the Honsang in the west. The Honui system has been changing through the ages, and here we followed the descriptions in <Ossiseochan (吳氏書 纂) $>$ to craft one of lacquered wood. The Honsang system has a body of lacquered cloth which is shaped round like a cannonball with a circumference of 10 Cheok 8 Chon 6 Bun. The Do and Bun scales on the sky are marked in in horizontal and vertical lines, with the equator in the middle and the ecliptic intersecting at an angle of a little less than $24 \mathrm{Do}$. A number of stars other than the five greatest stars are represented to make one revolution with one further degree per day. A sun model is hung on the ecliptic ring, which moves backward one degree per day to match the celestial movement. The automatic mechanism of the machine using the water is covered and hidden. ${ }^{2}$

According to this record, those Honui and Honsang were installed together, which might be explained in two different arrangements (Fig. 1); (a) with a power system in the leftmost position, (b) with a power system between the Honui and Honsang. We assume these two possibilities since the exact position of the power system remains unknown with only the descriptions on the arrangement of Honui and Honsang in the record.

We concentrate on Honsang in this paper. The globe of Honsang was made of lacquered cloth. The shapes of supporting frame and axes are unknown regarding the inside structure of the globe. The outer circumference of the Honsang was 10 Cheok 8 Chon $6 \mathrm{Bun}^{3}$. Since this perimeter is converted to 2,248.02 $\mathrm{mm}$ with a scaling factor of 1 Cheok= $207 \mathrm{~mm}$ (Nam 1995), the diameter of the globe is

$$
2,248.02 / \pi=715.56 \mathrm{~mm} \fallingdotseq 71.6 \mathrm{~cm} .
$$

The fact that the Do and Bun (度分) marks in horizontal and vertical lines represent the lines of longitude and latitude of the celestial sphere implies that those marks represent a concept of time zone and indicate $D o$ and Bun (度分) for the equator and the ecliptic. However, it is unknown how 1 Do (度) split into a finer scale or how many ticks were grouped in the system of 365.25 degrees which was Jucheondo (周天度; circumference of celestial globe) at that time. ${ }^{4}$ There is no information about which star chart (celestial map) was referred to for the positions of stars, i.e. details on the constellations and the number of stars, either.

The intersection angle of the equator and the ecliptic was written as '24 Do Yak (二十四度弱)' in the record. ${ }^{5}$ According to the almanac data by Korea Astronomy and Space Science Institute (2011), the intersection angle of the ecliptic decreases by $0.00000036 d$ per day. ${ }^{6}$ Considering

\footnotetext{
$2\ulcorner$ Sejong sillok」77:9b:line 11 line 16; 表西建小閣置渾儀渾象儀東象西渾儀之制歷 代不同今依呂氏書纂所载漆 木鷂儀渾象之制漆布爲體圓如彈丸圍十尺八寸六分縱横畫 周天度分赤道居中黃道出入赤道內外各二十四度弱徧布列舍中外官星一日一周而過一度 用「経絡於黃道每日却行一度與天行合其激水機運之巧「隱不見。

${ }^{3} \mathrm{Hahn}$ et al. (2001) regard this value as a typo of 10 Cheok 9 Chon 6 Bun where 3 Bun make 1 Do in the system by Wang Bun (王蕃). Divided by 3 Bun, 10 Cheok 9 Chon 6 Bun corresponds to approximately 365.33 which is almost the same as the length of one year and can be represented using the scale of 365.2575 . With this value, the diameter of Honsang would be approximately $72.2 \mathrm{~cm}$.

${ }^{4}$ In Gukjoyeoksanggo and Seowoongwanji from the latter part of the Joseon dynasty, the descriptions on the scale of Jeokdokyeongeuiui (赤道經緯儀) determined the range by the $5 \mathrm{Do}$ scale limit and the $10 \mathrm{Do}$ scale limit.

${ }^{5}$ The expression of Yak (弱) is interpreted as an addition of $11 / 12$ to 24 Do or as a subtraction of $1 / 12$ from $24 \mathrm{Do}$. Ahn et al. (2006) argue for the latter opinion, and this results in approximately $23.91 \mathrm{Do}$. Then this value is converted into $23^{\circ} .58$ in the current system of 360 degrees. It would be $24^{\circ} .56$ by the former opinion.

${ }^{6} d=$ JD -2455926.5 = elapsed days since midnight on January 0, 2012.
} 
this fact, it is appreciated that the intersection angle on the Honsang is close to the mean value of $23^{\circ} .437719$ to the modern knowledge.

Stars on the celestial sphere make one revolution and move further by one degree in a day. This description on the celestial movement is from the point of view with the earth at the center of the reference frame. An exact astronomical explanation for this situation is that one rotation of the earth for a day takes 23 hours 54 minutes 4 seconds ( 1 sidereal day). Rotation during 24 hours would be a little bit more than one turn. This is owing to the fact that the earth revolves around the sun while it rotates.

The sun's movement on the ecliptic on the Honsang is controlled by a string, where the sun moves backward by one degree on the ecliptic every day. The stars on the Honsang, with respect to the horizon, rise in the east, pass through the culmination, and set to the west. During the daytime, the sun tracks on the ecliptic while the Honsang works. The backward motion of the sun on the ecliptic by one degree per day, however, means that the sun moves one degree on the ecliptic in the opposite direction to the stars. By these movements, the positions of celestial objects (the constellations) change when viewed from the earth at the same time every day.

The movement of Honsang was designed to represent the effective motion of the celestial sphere and the sun resulting from the combination of rotation and revolution of the earth. The power mechanism for this instrument operation was called 'Gyeoksugiwoon (激水機運)' in which water was used for power of water wheels. The water-hammering method was a typical system for power generation in Joseon. This method was adopted by Heumgyeonggaknu (欽 敬閣漏, or Ongnu) in the early part of the Joseon dynasty, Honcheonsigye (渾天時計; armillary clocks) by Choi $\mathrm{Yu}$-Ji and Lee Min-Cheol in the middle, and Honsangui (渾象儀) by Hong Dae-Yong in the latter period. Shui yün i hsiang t'ai (水運儀象臺; manufactured circa 1092) by Su Song (蘇頌) and Han Gong-Lian (韓公廉) in China is well known as a clock work using this water-hammering method.

The record in $\ulcorner$ Sejong sillok」 on the specifications of Honsang and the movement of the sun is also mentioned in Sangwigo (象緯考) of Jeungbomunheonbigo (增補文獻備考) in the latter part of the Joseon dynasty and Gukjoyeoksanggo (國朝曆象考) published by Seo Ho-Su (徐浩修, 1736 1799), Seong Ju-Deok (成周惪), and Kim Yeong (金泳) in the latter period. ${ }^{7}$ The records in $\ulcorner$ Jeungbomunheonbigo $\lrcorner$ and $\ulcorner$ Gukjoyeoksanggo $\lrcorner$ are brief versions with a few modifications from that in $\left\ulcorner\right.$ Sejong sillok $k_{\lrcorner}$, omitting the part on the use of a 'string (䋲)' regarding the sun's movement. Other than these records, 「Jegayeoksangjip」(諸家曆象
集) by Lee Sun-Ji (李純之, 1406 1465) in the early period of the Joseon dynasty contains descriptions on Honsang in its record about the Uisang (儀象) system in the Chinese history. ${ }^{8}$ However, no such power system is mentioned there as in the record of $\left\ulcorner\right.$ Sejong sillok $k_{\lrcorner}$.

A Honsang was newly built in 1526 (the 21st year of King Jungjong). The record on the new Honsang in $\ulcorner$ Jungjong sillok」(中宗實錄) is as follows.

\section{The 20th Year of KingJungjong (1525) October 19th (Gap Jin)} Jeong Won said, “Lee Sun, Saseong (司成) at Seonggyungwan (成均館) had obtained a new book in China on the weather variability, which is about observation of celestial objects and titled <Mokryun (目輪) >. Lee Sun offered today what he had crafted before referring to the descriptions in $<$ Mokryun> when he was at Gwansanggam (觀象監) as a Gamsugwan (監修官) for Honui (渾儀) and Honsang (渾 儀). As this is a new and highly sophisticated instrument, could we make another set and test it at Gwansanggam?", then the king gave the order, "Execute as you suggested."

\section{The 21 st Year of King Jungjong (1526) May 11 th (Gye Sa)} The Gwansanggam (觀象監) said, “The Ganui (簡儀) and Honsang (渾儀) was manufactured in the period of Sejong, and having only one instrument for astronomical observations is not so much convenient. We cannot repair it either without a replacement for climate observations. Thus, we made a request to craft another one, and now it is completed. But, the current instrument is so old that some stars are missing and some lacquer has been peeled off. How would you think of fixing its displaced parts and letting a craftsman repair it? Also, I would like to ask you where to keep the old instrument.", then the king gave the order, "Execute as you suggested. Keep the fixed old instrument at Nae-Gwansanggam (內觀象監).”

The Honsang made in 1526 was probably a system of water-hammering method since the record was the first one

\footnotetext{
$\ulcorner J e u n g b o m u n h e o n b i g o\lrcorner$ Sangeuigo 2:24a:line 9 b:line 2; 渾儀渾象之制渾儀則依 元儒吳澄書纂言所載漆木鵎之渾 象前漆布爲體圓如彈丸圍十尺八寸六分縱横畫周天度 分赤道居中黄道出入赤道內外各二十四度弱徧列中外官星一日一周而過一度経日於黃道 每日却行一度與天行合激水機輪藏而不見. 「Gukjoyeoksanggo $3: 13 \mathrm{~b}$ : line 10 14a: line 5; the same record is in Sangeuigo of 'Jeungbomunheonbigo (Sangeuigo 2:24a:line 9 b:line 2) with the only difference of writing “蔵' instead of ‘藏' which has the same meaning.

${ }^{8}\ulcorner$ Jegayeoksangjip $\lrcorner$ Uisang vol.2.

9 「Jungiong sillok 55:41a:line 10 line 13. 政院棨日成均领司成李純 得革象新書 於中原其書鷂觀天之器名日目輪李純向以渾儀渾象監修官在觀象監因目輪之制而 造作今日進上矣此器極爲新巧請加作一件以置觀象監驗之何如傳日依啓; Mokryun (目輪) mentioned in the record is considered to indicate an astronomical instrument.

${ }^{10}\left\ulcorner J u n g j o n g\right.$ sillok $k_{\lrcorner}$57:5b:line 5 line 9; 觀象監啓日簡儀渾象世宗朝所造也觀天之器 只有一件未便若又修補則 無測候之具故前日請加造一件而今又畢造但舊象排置星辰及 着漆處今或剝落請以新象排設校正其差違而令匠人仍修補何如且一象藏之何所踥稟傳日 依啓修補一件置于內觀象監可也.
} 


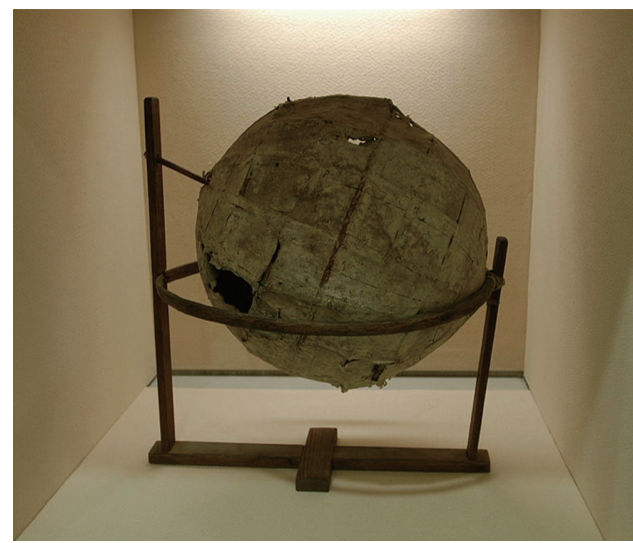

(a) Dosanseowon's Honsang

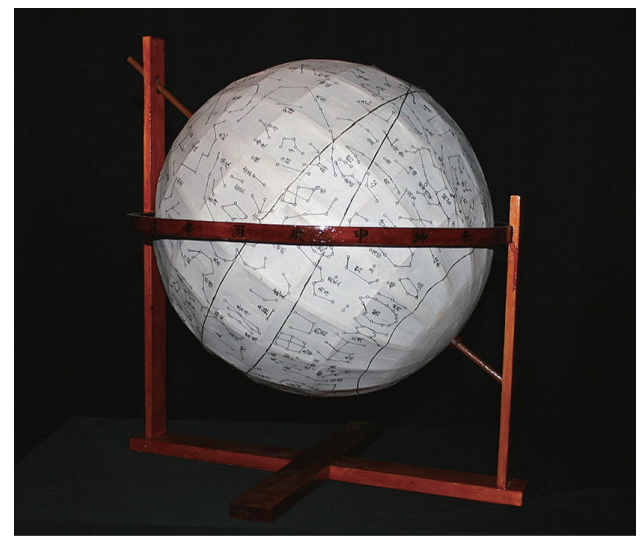

(b) Restoration product

Fig. 2. Artifacts of Honsang in Korea.

after the manufacturing record of the water-hammering type Honsang in 1435 and it mentioned that there had been only one instrument from the period of Sejong. Here, it is interpreted that the Honsang was manufactured together with Honui. Considering that the title of Lee Sun (李純) around 1525 was Gamsugwan (監修官) who was in charge of supervising the repair work for Honui and Honsang, and that the Honsang was built in the following year, 1526, the name, Honsang, at that time was presumably used for both Honui and Honsang together. Jeon (1994) deduced that 'Ganui' in the phrase of 'Ganui.Honsang (簡儀渾象)' in the record on May 11th (Gye Sa) in 1526 (the 21st year of King Jungjong) should have meant Honui. The reason is thought to be the expression of 'Uisang (義象)' instead of 'Ganui.Honsang' in the record of $\ulcorner J e u n g b o m u n h e o n b i g o\lrcorner$ regarding the 21st year of King Jungjong. ${ }^{11}$ The important fact seen in these two records in $\ulcorner J u n g j o n g ~ s i l l o k\lrcorner$ is that a new Honsang was manufactured in 1526 and the old Honsang from the Sejong era was repaired and moved to Gwansanggam in the palace. It is highly probable that the new Honsang was a waterhammering type system of Honui.Honsang.

\footnotetext{
The 8th Year of King Myeongjong (1553) May 7th (Im Ja) Sim Yeon-Won, An Hyeon, and others were awarded and the grades of Heo Yeop, Kim Yeo-Bu, and others were raised. The king gave the order to Jeong Won. "Award Dojejo (都提調) Sim Yeon-Won (沈連源), Jejo An Hyeon (安玹), Bujejo Yun Chun-Nyeon (尹春年), and others at Honsang Gyojeongcheong (渾象校正廳) well-tamed steeds, raise the grades of Nangcheong (郎廳) Heo Yeop (許 瞱), Bak Min-Heon (朴民獻), Kim Yeo-Bu (金汝浮), Bak Yeong (朴詠) and others, and reestablish Jo Seong (趙晟) to Jubu at Dongban (東班)."12
}

According to Myeongjong sillok (明宗實錄), the staff at Honsang Gyojeongcheong (校正廳; repair agency) received awards. The instrument which was fixed at Gyojeongcheong is highly probably the new Honsang that had been made in 1526. The old Honsang was repaired when they crafted the new Honsang in 1526. Considering that the old, fixed Honsang was sent to Nae-Gwansanggam, it is thought that they sent only the Honsang itself without the waterhammering mechanism. Thus, we suppose that its level of trouble or repair should have been much lower than in the case of a water-hammering type Honsang which was coupled with a mechanical device. On the contrary, the repair at Honsang Gyojeongcheong must have been a large scale work considering that they had even established a specialized agency for that repair. Therefore, we conclude that it should be the new Honsang made in 1526 and all of its mechanical parts what was repaired at Honsang Gyojeongcheong in 1553.

\footnotetext{
${ }^{11}\ulcorner$ Jeungbomunheonbigo $\lrcorner$ Sangeuigo 2:33b:line 2 b:line 5; 二十一年重修舊儀象 更製副件. 觀象監上言日今儀象諸器皆. 世宗朝所期星辰位置間或剝落請修補又言諸儀象 皆單件故若值修補時則無他測候之具請更造副件. 上站從之又命副件置于內觀象監. ${ }^{12}\left\ulcorner\right.$ Myeongjong sillok $k_{\lrcorner}$14:50b:line 3 line 5; 傳于政院日渾象校正都提調沈連源提調 安玹副提調尹春年賞熟馬 郎廳許嘩朴民獻金汝孚朴詠降品趙易東班主簿敍用.
}

\section{ARTIFACTS IN KOREA AND OTHER COUNTRIES}

\subsection{Artifacts of Honsang in Korea and Honsang Modelling}

The only remaining Honsang in Korea is the artifact at Dosanseowon (Dosan Confucian Academy). We conducted a scientific investigation (2006) on it, and measured the relic 


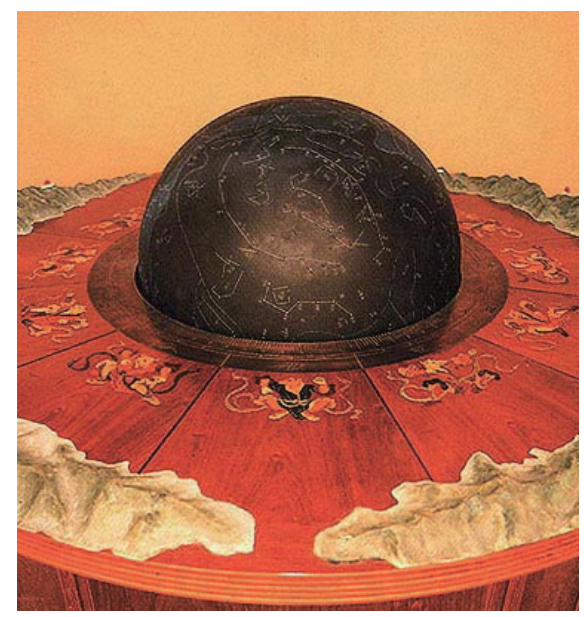

Fig. 3. The Silla Arts and Science Museum (in Gyeongju-si).

and restored it (Fig. 2).

A number of efforts have been made in Korea to restore the Honsang in the Sejong era. Most of them analyzed the manufacturing technic referring to Chinese artifacts. The first model among them is the Honsang crafted by the Silla Arts and Science Museum (modeled by Prof. Nha Il-Seong, made in 1994; Fig. 3). Cheonsang Yeolcha Bunyajido was used to determine the positions of constellations. Stars were represented using cubic, in different sizes depending on the brightness of star. This model was operated by electric power using a stepping motor.

Other models after that were manufactured mainly for outdoor exhibitions (Fig. 4). Starting from the Honsang installed at the Korean Studies Advancement Center (in Andong-si, made in 2000, for the outside), several Honsang models were crafted in slightly different sizes and shapes.
Bronze models of Honsang were built at Yeongreung (in Yeoju-gun, made in 2004, for the outside), the Gwacheon National Science Museum (in Gwacheon-si, made in 2008, for the inside), Jang Yeong-Sil Science Garden (Busan metropolitan city, made in 2010 , for the outside), and the Museum of Silhak (in Namyangju-si, made in 2011, for both the inside and the outside). ${ }^{13}$

The slightly different appearances of the Honsang models are considered to originate from that there is no extant artifact and they had to refer to Chinese relics with creating an aesthetic appearance using Korean motives. Thus, it is important to analyze the manufacturing method of each model and derive a standard model.

\subsection{A Variety of Honsang Artifacts in China and Japan}

\subsubsection{Honsang in China}

Shui yün i hsiang t'ai in China was completed by Su Song and Han Gong-Lian in North Song (北宋) circa 1092. ${ }^{14}$ In this facility, Honui and Honsang were driven by a co-operation of power devices such as water clocks, water wheels, and gear mechanism. It seems that such a system was introduced to Joseon and influenced the operating mechanism of the Honui and Honsang (made in 1435) installed to the west of Ganuidae (Kim 2007).

Shui yün i hsiang t'ai is a 3-story facility with a height of about $12 \mathrm{~m}$ and a length and width of $7 \mathrm{~m}$ each (Fig. 5).

${ }^{13}$ The constellation coordinates of Cheonsang Yeolcha Bunyajido were applied to the Honsang models at the Korean Studies Advancement Center, Yungneung and Jang Yeong-sil Science Garden, while the model at the Museum of Silhak is based on the constellation coordinates from ${ }^{\ulcorner}$Seongkyeong (星鏡)」 by Nam Byeong-Gil (南秉吉, 1820 1869).

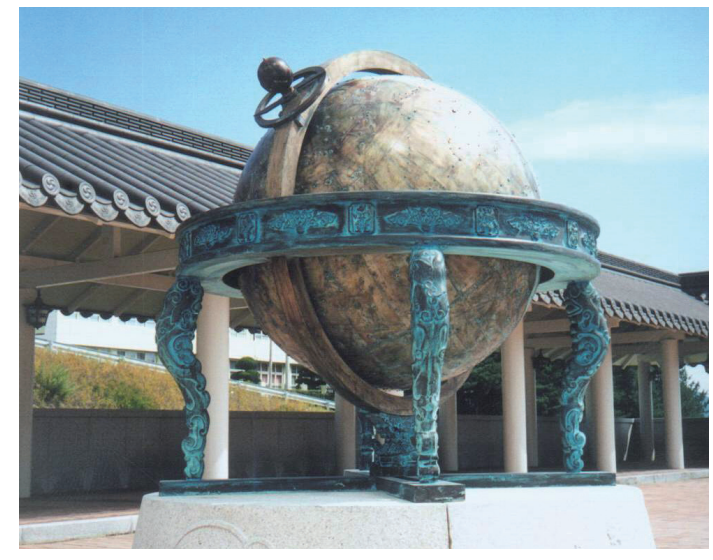

(a) The Korean Studies Advancement Center (in Andong-si)

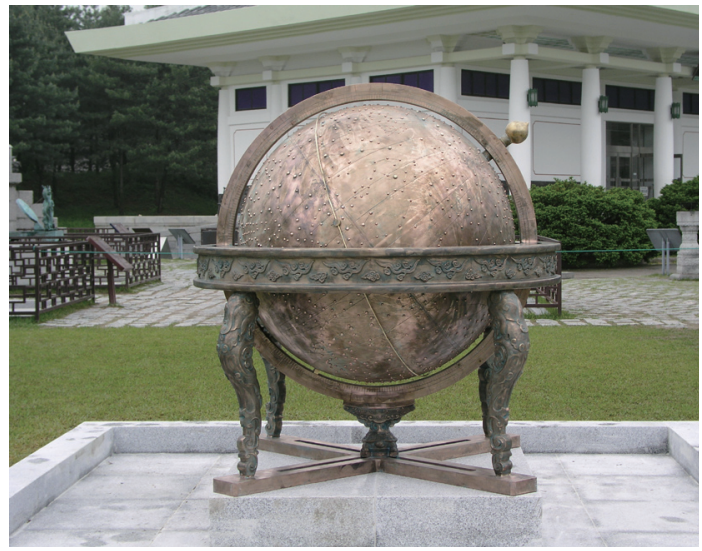

(b) Yeongreung (in Yeoju-gun)

Fig. 4. Restored models of Honsang for outdoor exhibitions. 

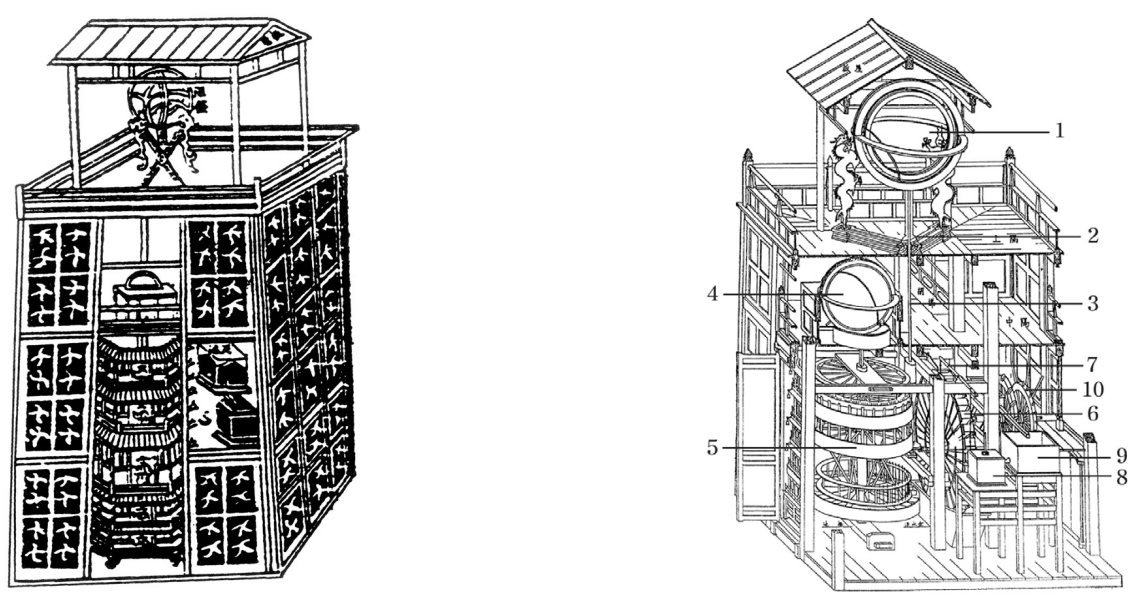

Fig. 5. Shui yün i hsiang t'ai's outward view (「Xinyixiang Fayao $)$ and sectional view (Pan 2003). 1: Honui (渾儀), 2: Oun and Gyupyo (鳌雲, 圭表), 3: Cheonju (天柱), 4: Honsang and Jigeo (渾象, 地柜), 5: Ju-Ya Giryun (書夜機輪), 6: Churyun (樞輪), 7: Cheonghyeong and Cheonswae (天衡, 天鎖), 8: Pyeongsuho (平水壹), 9. Cheonji (天地), 10: Hacha, Cheonha and Seungsusangryun (河車, 天河, 乘水上輪)

$\ulcorner$ Xinyixiang Fayao」 presents the outward appearance of Shui yün $i$ hsiang t'ai and its part designs. Pan (2003) shows main parts of Shui yün i hsiang t'ai in a sectional view. In this diagram, a time-signal device and a power device are installed on the lower floor of Shui yün i hsiang t'ai, the Honsang on the middle floor, and the Honcheonui (armillary sphere) on the upper floor. The automatic mechanism was powered by water at the water clock and connected through complicated mechanical wheels to the Honui, the Honsang, and the time-signal device.

There remain artifacts since 17th century for other than the water-hammering systems. There are 8 sets of astronomical instruments at the Beijing Ancient Observatory in China which were manufactured by western missionaries in 17th. This observatory keeps a Honsang which was made in 1673 in the Qing dynasty (Fig. 6). This Honsang is composed of several rings. A horizontal ring and a meridian ring are cross attached, and there is a polar ring (with a 96Gak timescale engraved) at the position of the north pole. A uniquely shaped rod is hung on the ceiling, to which a device for measuring altitude is connected.

The horizontal ring has a water groove on it for leveling and various patterns on its side. There are four dragon-

\footnotetext{
14蘇頌, r新儀象法要」, 四庫全書, 宋.; Shui yün i hsiang t'ai is thought to have been built in 1088 or 1089 or 1092, where 1092 is mostly accepted. Hong-sen Yan and Tsung-Yi LIn, "A study on ancient Chinese time law and the time-telling system of Su Song's clock tower," Mechanism and Machine Theory, 37, 1(2002), p. 15; this paper supposes that Shui yün i hsiang t'ai was built in 1088. Gao Xuan, "Principle Research and Reconstruction Experiment on the Astronomical Clock in Ancient China," Proceedings of the 11th World Congress in Mechanism and Machine Science, August 18 21(2003); This paper considers that Shui yün hsiang t'ai was built on January $16^{\text {th }}, 1089$ but completed in 1092 since it states that technology for all the components was not complete until 1093 when the book`Sinuisangbeobyo」 was finished. The operation of Shui yün i hsiang t'a lasted only 35 years owing to a war.
}

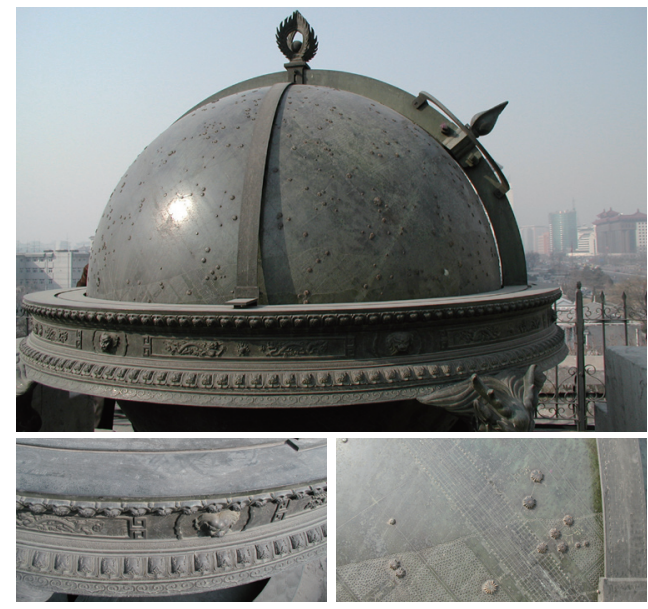

Fig. 6. Ferdinand Verbiest (1623 1688)'s Honsang (The Beijing Ancient Observatory).

pillars under the horizontal ring and a meridian ring going north-south through the horizontal ring. The meridian ring has a scale with diagonal lines at 1 degree interval, which enables a precise measurement. Marks of stars were crafted in different sizes depending on the brightness of star. A mark of the Milky Way and scales of the equator and the ecliptic are engraved on the surface of the globe. Under the meridian ring of this Honsang, there is a gear mechanism to adjust the altitude of the north pole on the Honsang globe.

There is another Honsang manufactured in the Qing dynasty at the Purple Golden Mountain Observatory (Fig. 7). Its appearance is similar to the artifact at the Beijing Ancient Observatory. However, it has neither a polar ring at the north pole position nor a polar rod on the ceiling. The horizontal ring has a water groove, and engraved marks 


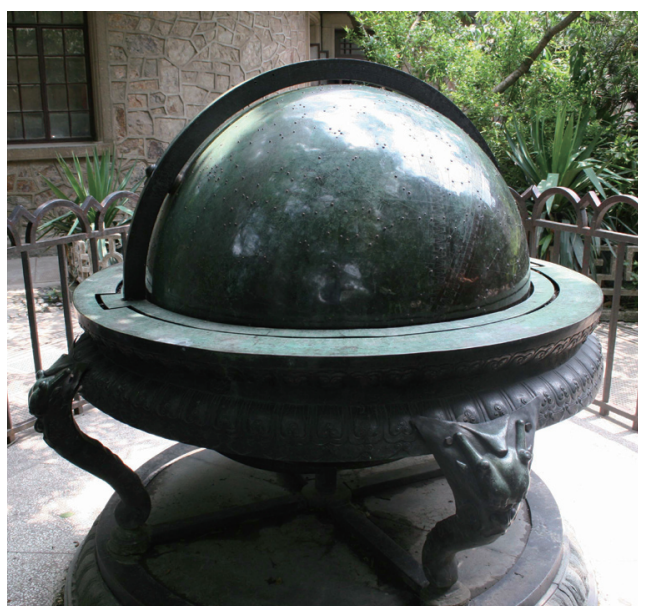

Fig. 7. Honsang, at the end of the Qing Dynasty (1905) (The Purple Golden Mountain Observatory).

such as a 360 -degree scale and a 96 -Gak scale on it. An equator ring and an ecliptic ring are engraved on the globe surface. The equator, ecliptic, and horizontal rings have 1-degree diagonal lines engraved on them, each line of which is divided into 6 parts.

\subsubsection{Honsang in Japan}

There remain relatively various artifacts of Honsangin Japan. Nha et al. (1994) introduce 14 sets of Japanese Honsang. Most of them have a horizontal ring and a meridian ring, and constellations drawn on a paper surface. In most cases, the celestial globe is composed of a wooden frame and paper on it. Considering their portable sizes, it seems that they were manufactured for academic or educational purposes. Here, we introduce the most typical 4 sets of Honsang among those presented by Nha et al. (1994), with some descriptions (Fig. 8).

\section{STUDY ON THE STRUCTURE OF THE WATER-HAMMERING TYPE HONSANG FOR RESTORATION: CONCEPTUAL DESIGN}

As there is no remaining artifact in Korea of the waterhammering type Honsang, our study here is based on the literature in Korea and the existing artifacts and records in China and Japan.

\subsection{Discussion on the Components and Manufacturing Methods of Honsang}

The power device of water-hammering method developed in 1435 operated Honui and Honsang together. Hahn et al. (2001) consider that this power system was in a parallel structure with Honui and Honsang arranged in a line. In this study, we discuss mainly on Honsang and the driving device of water-hammering method, excluding Honui.

The Honsang globe is composed of marks of constellations, their names, the Milky Way, the equator, the ecliptic, and a sun device and a movement device. Four pillars and a horizontal part support Honsang. The inside of the Honsang globe is made by attaching several layers of clothes on a wooden frame and applying lacquer on it. Nha et al. (1994) sand papered the surface since that resulting from the traditional method was rough. A disadvantage of the Honsang globe made of the wooden frame and lacquered clothes is its heavy weight, but it is not a trouble to make it rotate as long as the entire globe is kept in balance. If restoring a Honsang globe now, fiber glass reinforced plastic
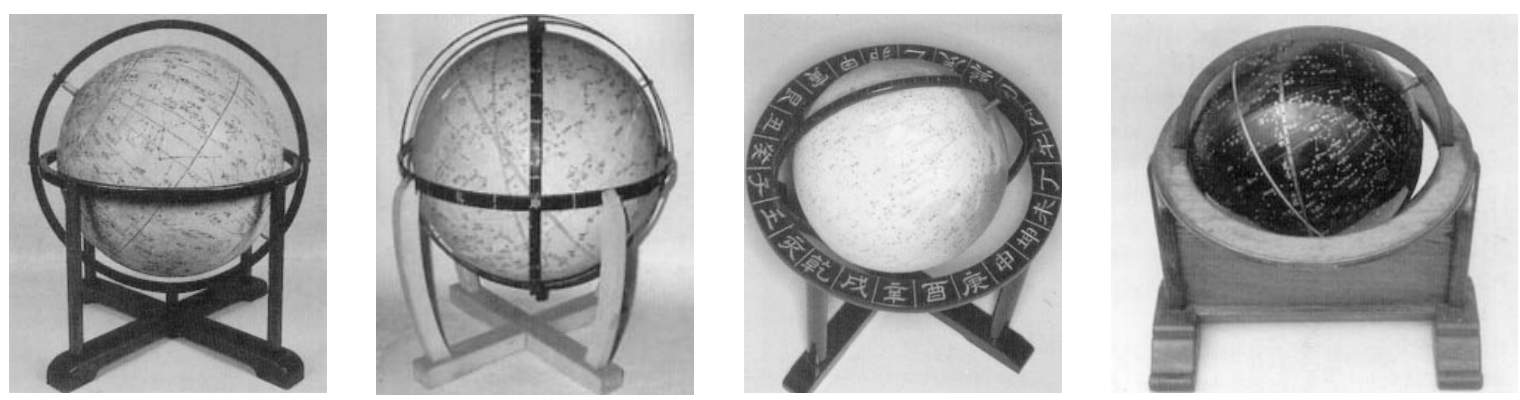

Fig. 8. Artifacts of Honsang in Japan (Nha et al. 1994). (a) The celestial equator and the longitude lines are shown on a $3 \mathrm{~cm}$ in diameter white celestial globe and names of fixed stars and constellations are also shown on. Meridian ring is attached on the pedestals and the material of pedestals is unidentified. (b) It was made of plaster and made by Murayamateiji (村山禎治, 1832 1922). The graduations at intervals of 5 degrees are marked on the meridian ring and the graduations at intervals of 30 degrees are marked on horizontal ring. (c) The 24 directions are shown on wide horizontal ring as the Chinese character instead of angles. The specific diameter is ascertained. (d) Its maker and age are unidentified. The silver inlaid celestial equator, ecliptic and constellations are shown elaborately on a $27.4 \mathrm{~cm}$ in diameter wooden celestial globe. 


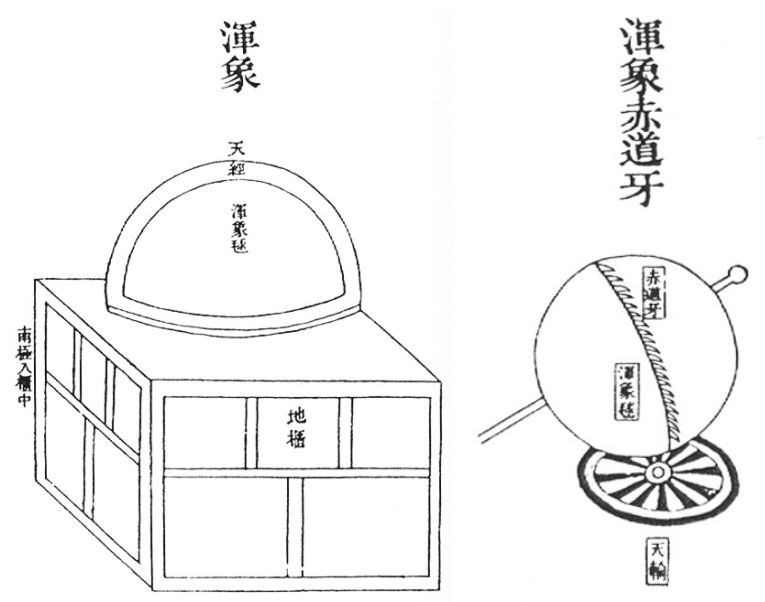

Fig. 9. The outline of Honsang and internal Cheonryun device ( $\ulcorner$ Xinyixiang Fayao $\lrcorner$ ).

or bronze can be considered for the material to enhance its durability and minimize any deformation. The Honsang models manufactured for outdoor exhibitions in Korea are mostly made of bronze and, although have no driving system, can be turned by hand.

The Honsang globe is supported by the combination of a horizontal plane and the meridian ring. The structure of the horizontal plane can be designed as either such a horizontal ring type as in Honcheonui or a plane type as in the model (made in 1994) displayed at the Silla Arts and Science Museum. A basic configuration of this horizontal plane is placing a Honsang globe on a box as presented in $\ulcorner$ Xinyixiang

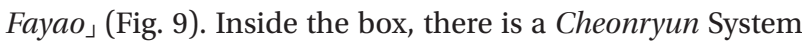
which makes Honsang rotate one turn a day. The scene of rising and setting stars on Honsang was created by hiding such a mechanical system. Liang Lingzan (梁令贊) in the Tang dynasty installed rings for tracking the sun and the moon on his Honsang (made in 724) and Zhang Sixun (張思 訓) in the Song dynasty made the shapes of the sun and the moon be seen on his Honsang (made in 979) (Hahn et al. 2000). However, Shui yün i hsiang t'ai in the period of North Song (北宋) included no parts for the sun's movement.

Lines of longitude and latitude (more exactly, the right ascension and declination) are drawn on the Honsang globe as a coordinate system for constellation drawings. Those lines are seen also on the existing artifacts in China and Japan even with slightly different formats. Most of the Honsang artifacts existing in Japan use 28-Su for the longitudinal lines. On the Honsang at the Beijing Ancient Observatory (made in 1673), traditional 28-Su lines of longitude are omitted and 24 longitudinal lines are drawn instead around the ecliptic pole at every $15^{\circ}$. And 13 latitudinal lines are drawn in parallel to the ecliptic line. On the Honsang made around the end of the Qing dynasty (1905), only 24 longitudinal lines at $15^{\circ}$ interval are marked. There are no latitudinal lines drawn on this Honsang. The Honsang in $\ulcorner$ Sinuisangbeobyo $\lrcorner$ presents 28 longitudinal lines, and constellations around the north pole and the south pole, separately (Fig. 10). No latitudinal lines are marked here, either. It is considered that they were omitted since the scale on the meridian ring can substitute the latitudinal lines.

Considering when the Honsang in the early period of Joseon was manufactured, it seems clear that they adopted the 28-Su lines of longitude from Cheonsang Yeolcha Bunyajido (made in 1435). It is not certain, however, whether they drew latitudinal lines or not. According to the record in $\ulcorner$ Sejong sillok $\lrcorner$, degree numbers were marked on the Honsang globe in horizontal and vertical lines. Considering the expression, it seems that the horizontal direction represent the equator line and the vertical direction the
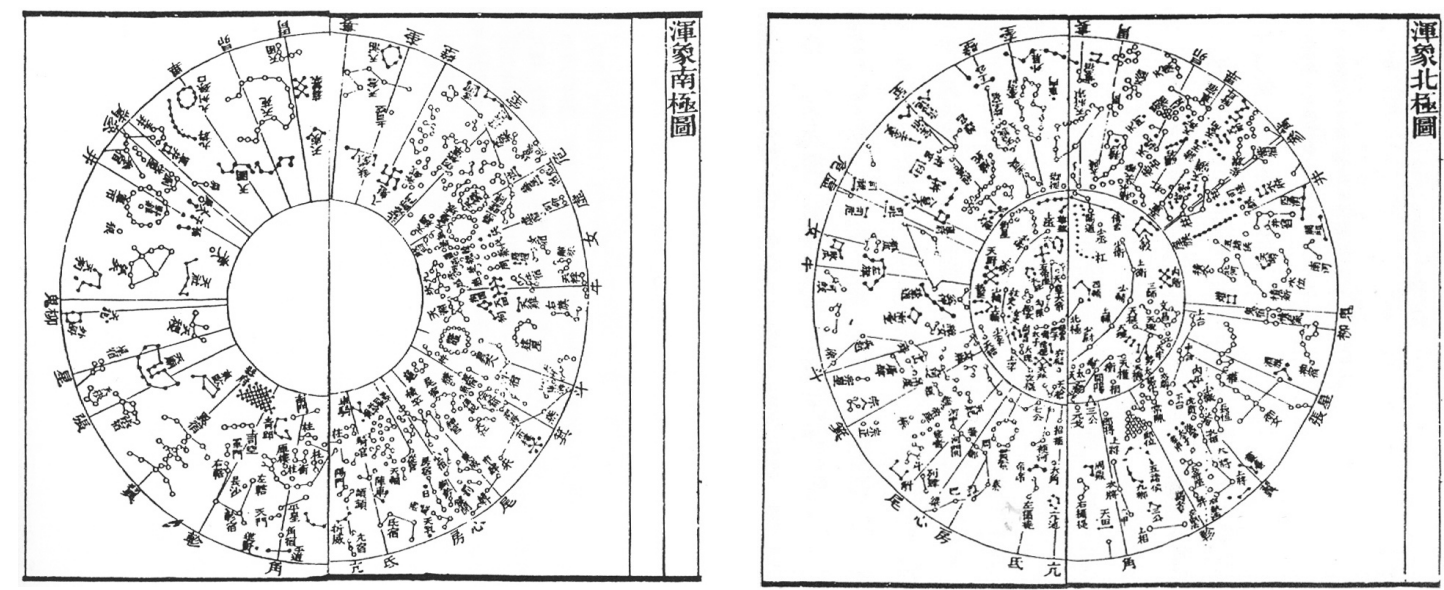

Fig. 10. Constellations around the north pole and south pole ( $\ulcorner$ Xinyixiang Fayao」 ). 


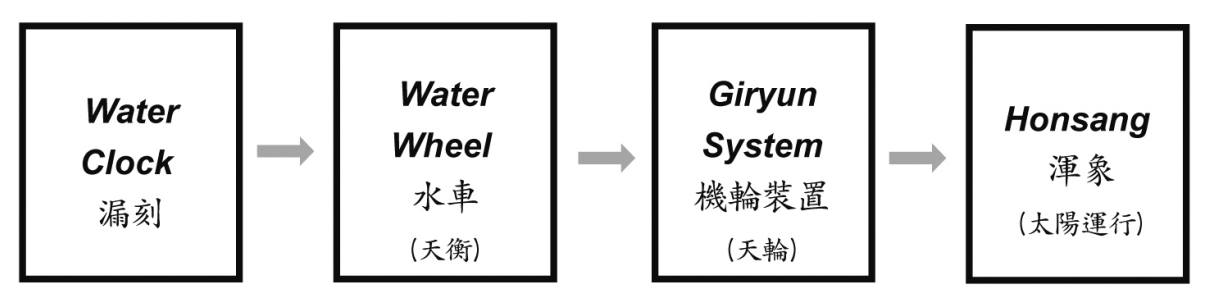

Fig. 11. Water-hammering power transmission system.

28-Su line. Although there is no record on a meridian ring, the ring must have been installed since the rotation axis of Honsang for its automatic operation should pass through the north and south poles of a meridian ring. Such a meridian ring is seen also on the Honsang presented in $\ulcorner$ Xinyixiang Fayao $\lrcorner$. Thus, it is considered that positions of celestial objects could be marked on the water-hammering type Honsang in the early period of Joseon using the scale of the meridian ring, even without latitudinal lines.

Besides the meridian ring, the equator should be represented on the Honsang globe. The equator can be drawn on the globe or formed in a ring; the equator ring. In the Chinese and Japanese artifacts, equator lines were drawn on the globes without any equator ring. The equator lines on the Chinese Honsang globes are presented as the scales of diagonal lines. Drawings of lines or small circles were used for the equators on the Japanese globes. The same formats were applied also for the ecliptic. Regarding the expression of the ecliptic on the Korean Honsang, it is not likely that a line was drawn on the globe considering the method of moving the sun. The sun model was actually moving along the ecliptic by one degree per day. Thus, it must be in a form of rail either in contact with or just above the globe surface. Such an example is the ecliptic ring of the existing artifact of Honcheonsigye (armillary clock; National Treasure of Korea No. 230). There is a ring for the sun's movement in the outer part of the ecliptic ring, where the sun is moved by pulling a string (Needham et al. 1986, Lee \& Kim 2007). Thus, it can be concluded that there was a part of the ecliptic ring for tracking the sun on the globe of the water-hammering type Honsang in Joseon. On the other hand, the equator is thought to have been expressed by a drawing on the globe as in the Chinese and Japanese cases.

It is highly probable that the constellation drawings on the Honsang globe reflect the observational measurements at that time. Cheonsang Yeolcha Bunyajido, crafted in 1395 (the 4th year of Taejo), contains constellations of two different ages. The constellations engraved within the circumpolar ring reflect the observational results at that time, while the constellations out of the ring are those seen around the 1st century (Park 1998). Thus, constellations at that time can be reproduced using the constellation positions in Cheonsang Yeolcha Bunyajido. Fortunately, Cheonsang Yeolcha Bunyajido was 3D scanned by the Korea Astronomy and Space Science Institute in 2008. ${ }^{15}$ Using such data, exact positions of constellations and sizes of stars can be reflected to a restoration of Honsang. There is no clear description on lines of constellations or shapes of stars. In the cases of existing artifacts, they were drawn or made of the same material and attached, depending on the material. The decision can vary depending on the location where the restored Honsang would be installed.

\subsection{Configuration and Operation of the Power System of Water-Hammering Method}

The power system of water-hammering method consists of a water clock, a water wheel, the Cheonhyeong system, the Giryun System, Cheonryun, etc. (Fig. 11). The water clock supplies a constant amount of water to Sususangs (small bowls) on the water wheel. Sususangs are connected to Cheonhyeong which is a kind of balance with weights and controls the water wheel. Power from the water wheel is sent through Giryun to Honsang for operation.

The role of the water clock is to supply water at a steady rate (refer to Water Clock in Fig. 12). Water clocks in the Silla era were 4-level compensating system (Lee et al. 2008). For Jagyeongnu (striking clepsydra) in the early period of Joseon, they used a water clock in a 3-level serial structure with one Dae-Pasuho (large-sized water supplying vessel) and two Jung-Pasuhos (medium-sized water supplying vessel) (Nam et al. 1998). The technology of the Three Kingdom Period was advanced considerably by the overflow device in Jagyeongnu. Among the water supplying Pasuhos, the lowest Pasuho has an overflow device at a certain height which keeps the amount of water constant. The water from the last Pasuho ('A' in Water Clock in Fig. 12) fills Sususangs, the

${ }^{15}$ Yang Hong-Jin (Korea Astronomy and Space Science Institute) measured the coordinates of stars on Cheonsang Yeolcha Bunyajido, National Treasure of Korea No. 230, accurately by 3D scanning, from 2008 to 2010 through the "study on the scientific features of Cheonsang Yeolcha Bunyajido, the National Treasure astronomical chart." 


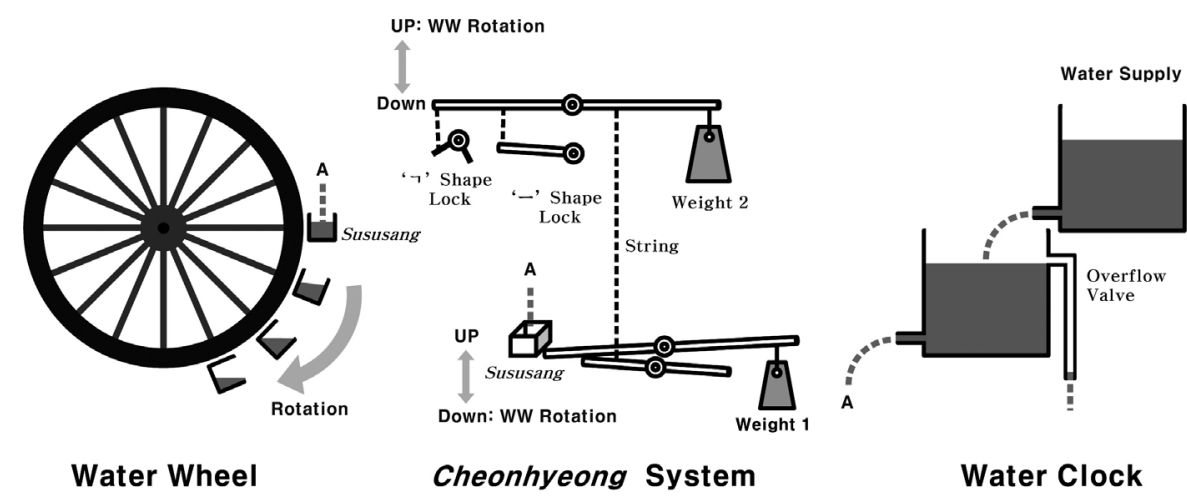

Fig. 12. Keys map of water wheel, Cheonhyeong system and water clock.

small bowls, on the water wheel.

The water wheel is turned by the weight of water in Sususangs, which are attached to the outer rim of the water wheel (refer to Water Wheel in Fig. 12). Park (2011) estimates the number of Sususangs as 12 or 16 in the water-hammering system of Honcheonsigye by Lee Min-Cheol in 1669. This result is from their comparison with the scale of water wheel of Shui yün i hsiang t'ai in China. In 「Jeungbomunheonbigo」, there is a record on the manufacturing details of the waterhammering type Honcheonsigye in 1669, which says that it was to restore the old system of Heumgyeonggak in the Sejong era. ${ }^{16}$ This implies that the water-hammering system in 1669 inherited the manufacturing technology from Heumgyeonggaknu in 1438. Based on this, Kim (2007) considers that the Honsang system of water-hammering method in 1435 was in a similar form as the power systems of Heumgyeonggaknu in 1438 and the water-hammering type Honcheonsigye in 1669. In conclusion, it is probable that the water wheel mechanism by Lee Min-Cheol is similar to the water wheel system in the water-hammering type Honsang.

The function of the Cheonhyeong system is to turn the water wheel when the weight of water in a Sususang reaches a certain level and to hold the water wheel steady while water is filling the next Sususang (refer to Cheonhyeong System in Fig. 12). This is similar to the function of foliots in mechanical clocks in Europe in 14th century. In a mechanical clock powered by weights, a foliot was an essential device controlling the falling speed of a weight to enable precise measurement of time. In China, the Cheonhyeong systems, with the concept of foliot, were used to control water wheels already in 11th century. When a certain amount of water ('A' in Fig. 11) filled a Sususang, the balance measuring weight of the Sususang (to which

${ }^{16}$ r Jeungbomunheonbigo」Sangeuigo 3:2a:line7; 祭酒宋浚吉請復銓敬閣古制.
Weight 1 is hung) is pushed down. Then, it pulls the upper balance for water wheel control (to which Weight 2 is hung) down, which release the locks holding the water wheel by pulling the ' $\neg$ '-shaped lock and the ' - '-shaped lock up. Now the water wheel moves down. After a while, the water wheel is stopped by the ' $\neg$ '-shaped lock and the ' - '-shaped lock, and a repeating operation of this process generates a constant power of rotation at the water wheel. Then the rotational power is transferred to the Giryun system.

The role of the Giryun system is to receive power from the water wheel and to transfer it to Honsang (refer to Giryun system in Fig. 13). In Shui yün $i$ hsiang t'ai in China, the force load on each gear device was probably large since it had to operate Honui and Honsang together including the timesignal device in a 5-level (floor) structure. On the contrary, in Joseon, Honui and Honsang formed an independent system, which was installed in a small house. Also the time-signal device and a part of the celestial movement were separated to become the Heumgyeonggaknu system. Thus it can be considered that the Giryun system, which was used only to drive Honui and Honsang, should have been operated with less power than that for Shui yün i hsiang t'ai. In the waterhammering type Honsang in Joseon, more gear parts and power were added to drive the device for the sun's movement.

The Honsang globe makes about one revolution per day (refer to Honsang in Fig. 13). The Honsang of Shui yün $i$ hsiang t'ai was turned by the gear device named Cheonryun. The Honsang globe had a toothed wheel at the equator and received power from Cheonryun located under it. The Honsan in Joseon was turned by a device with a similar function as Cheonryun. The existing Honcheonsigye receives the driving power from the axis of the north pole, and the remaining Honcheonui at the Korean Christian Museum at Soongsil University also receives its power from the northern part (Kim 2007). However, it seems reasonable to operate the Honsang using a gear device connected to the equator 


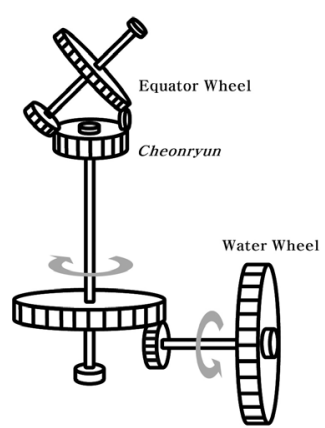

Giryun System

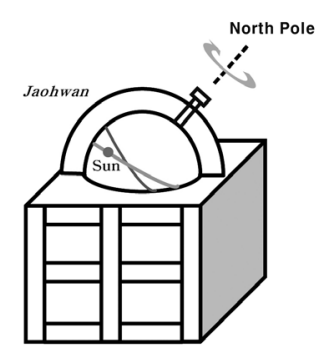

Honsang
Fig. 13. Keys map of Giryun system and Honsang.

or the axis of the south pole. As $\left\ulcorner\right.$ Sejong sillok $k_{\lrcorner}$describes on the operation of the Honsang as "The automatic mechanism of the machine is covered and hidden," it is more likely in a form of hidden gears in the south rather than a prominent device to the north.

\section{CONCLUSIONS}

The Honui and Honsang systems of water-hammering method in Joseon were installed together in Sogak (small house) to the west of Ganuidae in 1435. Later in 1526, new systems of Honui and Honsang were manufactured, and the previous systems were repaired and sent to Gwansanggam. There is a record on another repair of Honsang in 1553. However, this record mentions nothing about Honui. No record on the repair of Honui is found any more in the later literature (Kim 2007). Based on the records, it is considered that the tradition of operating Honui and Honsang of the water-hammering method together changed at that point.

The reconstruction models of Honsang in Korea have been built mainly for outdoor exhibitions. However, they can be sources of important technical information to refer to for manufacturing a restoration model of the water-hammering method, such as the marks of 28-Su longitudinal lines on the Honsang globe, the forms of the meridian ring and the horizontal ring, etc. Also, the 3D scanned data of Cheonsang Yeolcha Bunyajido, crafted in 1395, are expected to enable more accurate marking of the positions of constellations.

Shui yün i hsiang t'ai, built in China in 1092, is composed of a giant water wheel and a variety of gear devices. A set of Honui and Honsang was located on the 5-level structure of time-signal device. Unlike the tower-style Shui yün i hsiang t'ai, it is more likely that the Honui and Honsang in Joseon were positioned side by side in a parallel arrangement. Without a separate device for time-announcing, there seems to be no particular reason to locate them on a high place. Furthermore, considering the typical scale of Sogak in Gyeongbok palace, it is supposed that the water wheel was connected from one side of both the Honui and Honsang or located in the middle to distribute power to both sides.

The most important factor in the power system of waterhammering method is to control the water clock to have a constant water flow and consequently to make the rotational power of the water wheel constant. The use of the overflow devices and the development of the Cheonhyeong system enabled the precise operation of the water wheel. It seems that Jang Yeong-Sil adopted an idea for developing the water-hammering system in Joseon from Shui yün $i$ hsiang t'ai by Su Song and Han Gong-Lian (Nam 2002). Jang Yeong-Sil modified the structure of Shui yün i hsiang t'ai to meet our conditions. He separated the Honui and Honsang and placed them in Sogak, and installed Ongnu (jade clepsydra) in Heumgyeonggak which was a completely new type of astronomical clock with a time-signal device in a form of Gasan (imitation mountain). Also, he included the moving mechanism for the sun, which was not in the Honsang of Shui yün i hsiang t'ai, in the Honsang and Ongnu to automatically reproduce the sun's movement on the ecliptic.

Through the analysis on the structure of the waterhammering type Honsang, we investigated the water clock, the water wheel, the Cheonhyeong system, the Giryun system, the operation of Honsang, etc. Our study on such individual parts helped us understand the device of waterhammering method as an organically operating system. We established a basis for studies on the structure and operation of the water-hammering type system of Honui and Honsang for its reconstruction as well as studies on the structure of the water-hammering type Honcheonui in the future. Such studies on water-hammering type devices would achieve important results for restoration of various astronomical clocks in the entire period of Joseon.

\section{ACKNOWLEDGMENTS}

This work was supported by the research grant of the Chungbuk National University in 2010.

\section{REFERENCES}

Ahn SH, Choi YH, Kim SH, Determination of preliminary orbital elements of the great comet C/1665 in Korean history, JASS, 23, 55-70 (2006). http://dx.doi.org/10.5140/ JASS.2006.23.1.055 
Hahn YH, Nam MH, Lee SW, Water-operated armillary clocks of the Chosŏn Dynasty, J Korean Hist, 113, 57-83 (2001).

Hahn YH, Nam MH, Lee SW, Yi MK, Astronomical clocks of the Chosun Dynasty - King Sejong's Heumgyonggaknu, Technol Hist, 1, 99-140 (2000).

Jeon SW, Time, clock and history (Wolgansigyesa, Seoul, 1994), 117.

Kim SH, On the armillary sphere in the Uigijipseol, MS Thesis, Chungbuk National University (2002).

Kim SH, A study on the operation mechanism of Song I-Yŏng's armillary Clock, PhD Dissertation, Chung-Ang University (2007).

Korea Astronomy and Space Science Institute, Korean astronomical almnanc 2012 (Namsandang, Seoul, 2011), 111.

Lee YS, Jeong JH, Kim SH, Lee YB, Astronomical calendar and restoration design of clepsydra in the Silla era, JASS, 25, 299-320 (2008). http://dx.doi.org/10.5140/ JASS.2008.25.3.299

Lee YS, Kim SH, Study on the structure and working principle of Song I-yŏng's armillary clock, JASS, 24, 167-178 (2007). http://dx.doi.org/10.5140/JASS.2007.24.2.167

Nam MH, Korea Water-Clocks (Konkuk University Press, Seoul, 1995), 271-304.

Nam MH, Jang Yeong-Shil and the striking clepsydra Jagyeongnoo - revival on the time measuring history of Chosun period (Seoul National University Press, Seoul, 2002), 244-245.

Nam MH, Ju NC, Hahn YH, Hahn DY, Seo MH, et al. Borugak Jagyeognu's restoration model design - Cultural Heritage Administration Report (Konkuk University Korea History of Technology Institute, Seoul, 1998), 99166.

Needham J, Lu GD, Combridge JH, Major JS, The hall of heavenly records: Korean astronomical instruments and clocks 1380-1780 (Cambridge University Press, London, 1986), 138-145.

Nha IS, Kang YU, Kim YG, Park NS, Lee EH, et al. Honsang of King Sejong - Cultural Heritage Administration Report (Yonsei University Observatory, Seoul, 1994), 20-23.

Pan N, History of Chinese astronomical instruments (Shanxi-Jiaoyo Press, Taiyuan, 2003), 155.

Park CB, Analysis of the star map in Chon-Sang-Yol-ChaBun-Ya-Ji-Do, Korean J Hist Sci, 20, 113-132 (1998).

Park JH, A study on the flow control and escapement system of the water operated mechanical clock in Joseon Dynasty, MS Thesis, Chungbuk National University (2011). 